\title{
РОЛЬ НАЦИОНАЛЬНОГО ПРОЕКТА «ЭКОЛОГИЯ» В ИЗМЕНЕНИИ НЕБЛАГОПРИЯТНОЙ ЭКОЛОГИЧЕСКОЙ ОБСТАНОВКИ, СЛОЖИВШЕЙСЯ В РОССИИ
}

\author{
(c) 2021 Язев Ярослав Вячеславович \\ студент-магистр \\ Университет ИТМО, Россия, Санкт-Петербург \\ E-mail: yaroslav.v.yazev@gmail.com \\ (c) 2021 Павлюков Александр Викторович \\ студент-магистр \\ Университет ИТМО, Россия, Санкт-Петербург \\ E-mail: off.mail.pavlyukov.a.v@gmail.com \\ (c) 2021 Волков Александр Романович \\ преподаватель \\ Университет ИТМО, Россия, Санкт-Петербург \\ E-mail:volkovra@yahoo.com \\ (c) 2021 Павлова Елена Александровна \\ доцент, кандидат экономических наук \\ Университет ИТМО, Россия, Санкт-Петербург \\ E-mail: ea_pavlova@mail.ru
(c) 2021 Канунникова Кристина Игоревна
студент-магистр \\ Университет ИТМО, Россия, Санкт-Петербург \\ E-mail:ri_kri@mail.ru
}

В научной статье проведен анализ практической роли национального проекта «Экология» при обеспечении экологической безопасности в России. Рассмотрена краткая характеристика национального проекта «Экология», ее цели и целевые показатели. Проанализирован федеральный проект «Внедрение наилучших доступных технологий». Рассмотрены основные проблемы и барьеры реализации национального проекта.

Ключевые слова: экология, экологическая политика, экологическая безопасность, охрана окружающей среды, национальные проекты, проект «Экология», зеленые технологии, модель устойчивого развития.

Актуальность научных исследований на данную проблематику обусловлена тем, что экология и охрана окружающей среды становятся более важным вопросами на текущей повестке управления. Чтобы понимать примерную эффективность государственной политики в управлении экологической безопасности России необходимо проанализировать перспективы реализации национального проекта «Экология».

Современная природная экосистема и экология регионов Российской Федерации, где сосредоточена значительная часть объектов промышленного производства сталкиваются со следующими актуальными проблемами, среди которых:

- загрязнение атмосферного воздуха из-за различных аварий техногенного характера, лесных и степных пожаров и т.д.;

- размещение и захоронение отходов производства промышленных объектов, которое резко обострилось в последние годы;

- недостаточное финансирование в модернизацию технологий жилищно-коммунальных предприятий в сфере энергоснабжения, водоснабжения и водоочистки;

- рост выбросов СО2 из-за высокой доли промышленного сектора в структуре валового внутреннего продукта; 
- высокая степень износа основных фондов.

Для того, чтобы повысить уровень эффективности системы управления экологической безопасности для обеспечения устойчивого развития промышленных регионов нашей страны, необходимо достижение целей, поставленных в рамках национального проекта «Экология».

Главной целью национального проекта «Экология» выступает кардинальное решение и улучшение экологической обстановки с задачей положительного влияния на оздоровление и состояние здоровья россиян. Начало реализации данного национального проекта взято с 1 октября 2018 года, а срок длительности заканчивается 31 декабря 2024 года.

В рамках финансирования национального проекта «Экология» суммарно планируется затратить 4,041 трлн. рублей средств, из которых [3]:

- внебюджетные источники - 3,206 трлн. рублей;

- федеральный бюджет - 0,701 трлн. рублей;

- бюджеты субъектов РФ - 0,133 трлн. рублей.

Подробными целями реализации национального проекта «Экология» выступают [4]:

- увеличение количества ликвидированных несанкционированных свалок до 191 единиц;

- снижение уровня загрязнения воздуха выбросами промышленных предприятий;

- экологическая реабилитация водных объектов;
- введение 7 комплексов по обработке, утилизации и обезвреживанию отходов первого и второго класса опасности;

- снижение объема выбросов вредных веществ в городах России на 22\%;

- восстановление площади водных объектов до 23,5 тысяч гектаров.

Согласно статистической информации Росстата, представленной на рисунке 1 , в России наблюдается сокращение выброса веществ, которые загрязняют атмосферу нашей страны.

Стоит обратить внимание, что с 2015 по 2019 гг. выбросы вредных веществ в атмосферу снизились с 31,269 млн. тонн до 22,735 млн. тонн. В первую очередь, это возможно благодаря активной политике органов государственной власти по противодействию выбросов вредных веществ в окружающую среду со стороны промышленных объектов и компаний, осуществляемых в рамках реализации национального проекта «Экология».

Во-вторых, снижение выбросов веществ, загрязняющих атмосферу связано с увеличением бюджетного финансирования расходов на окружающую среду, которые за 2019 год составили 871,993 млрд. рублей. Подробная структура расходов на окружающую среду изображена на рисунке 2.

Одним из основных федеральных проектов, входящих в программу «Экология», считается «Внедрение наилучших доступных технологий». Причиной тому выступает то, что на данный проект выделено 2,427 трлн. рублей совместно-

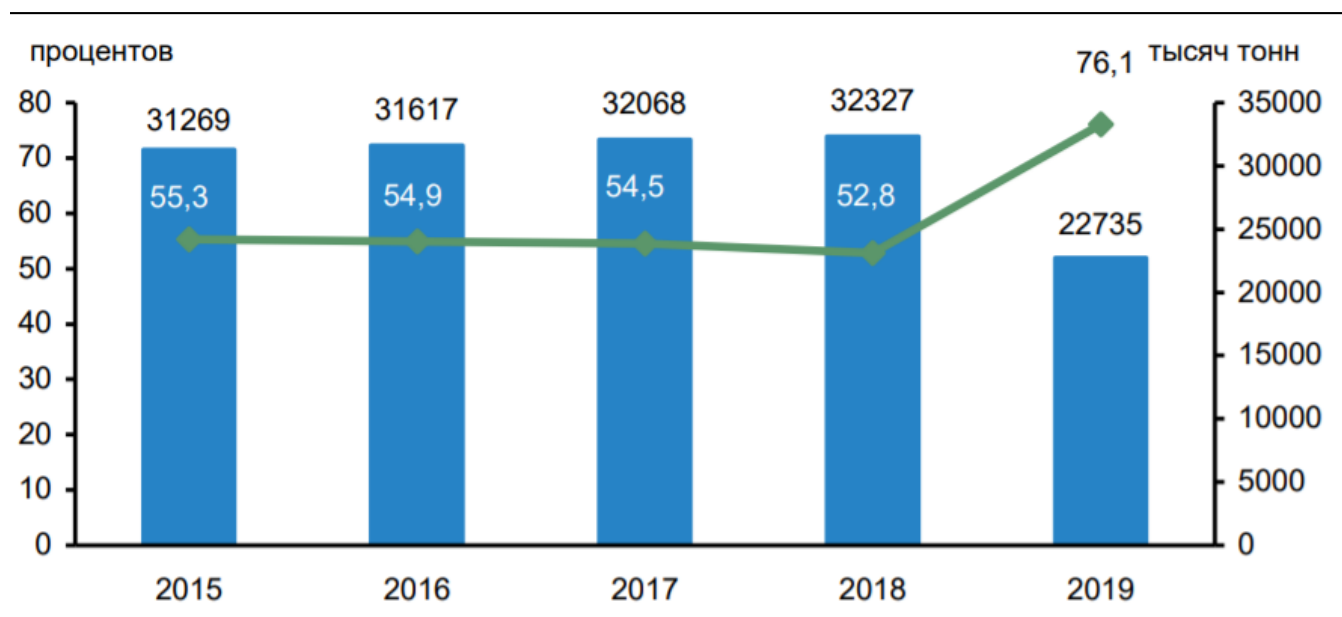

Выброшено загрязняющих атмосферу веществ стационарными и передвижными источниками

- Доля выбросов стационарными источниками

Puc. 1. Выбросы загрязняющих атмосферу веществ в России [2] 


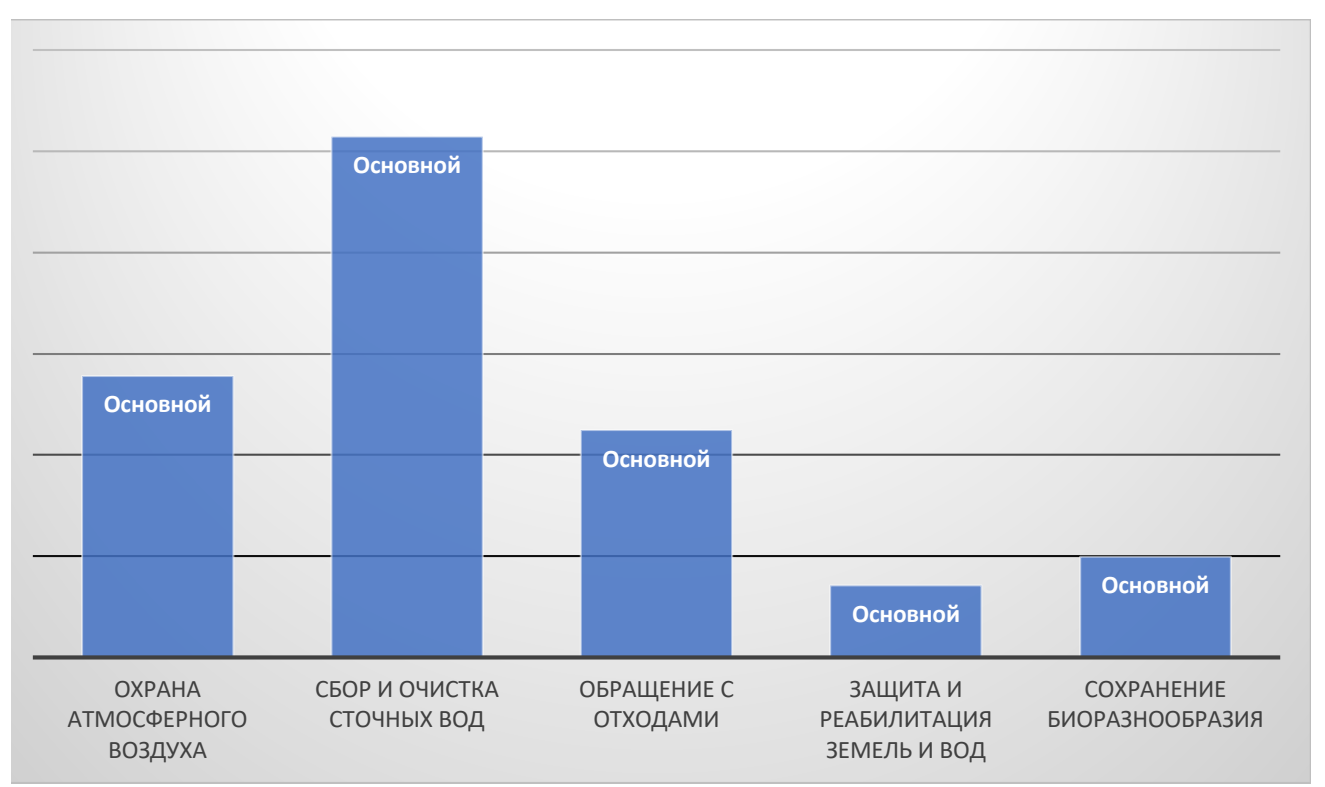

Puc. 2. Структура расходов на охрану окружающей среды в 2019 году в России, в млрд. рублей [1]

го финансирования. Это более половины всего бюджета национального проекта «Экология».

31 декабря 2020 года федеральный проект завершился досрочно и причиной тому послужили его следующие недостатки [5]:

1. Проект фактически разорван между четырьмя проектами - чистый воздух, чистая вода, инфраструктура обращения с отходами 1 и 2 категории и НДТ.

2. Ни одна задача федерального проекта не содержит в себе решение вопросов повышения технологичности и ресурсосбережения в промышленном производстве отечественных предприятий.

3. Федеральный проект выступает не внедренческим, а скорее всего, обслуживающим. При этом, на него выделена основная доля финансирования национального проекта «Экология».

4. Инвестиции в производство наилучших доступных технологий превышает допустимый совокупный спрос промышленных предприятий России на подобные технологии. Таким образом, инвестиции и финансирование данного федерального проекта себя бы не окупили.

На сегодняшний день, актуальность национального проекта «Экология» обусловлена тем, что ее механизмы формируют основы «зеленой экономики», как будущего вектора развития промышленного сектора национальной экономики России. Обусловлено это ростом роли устойчивой модели развития, при помощи которой формируются принципы энергосбережения и тенденция повышения эффективности функ- ционирования бизнеса, применяющего «зеленые технологии» в своем производстве. Важной задачей выступает трансформация характеристики «зеленой экономики», что позволит сформировать условия социально-экономического развития государства.

Главным преимуществом соблюдения концепции «зеленой экономики» промышленными предприятиями России является то, что внедрение принципов экологической безопасности требует разработки инноваций и зеленых технологий. Несмотря на необходимость капитальных расходов, их применение способствует повышению экономической эффективности производственной деятельности предприятий, что положительно сказывается на их финансовом результате [6].

Как итог, развитие «зеленой экономики»это стратегия экономически эффективного развития и бизнеса, ведь ресурсосбережение приводит к оптимизации затрат и повышению уровня рентабельности производства. Таким образом, степень экономической безопасности и финансовой устойчивости предпринимательских субъектов, которые применяют концепцию «зеленой экономики» при организации своей стратегии развития, повышаются.

Подводя итоги проведенного исследования, можно прийти к следующим заключениям:

1. Роль национального проекта «Экология» заключается в обеспечении экологической безопасности государства, повышения уровня экологичности промышленного производства 
и снижения выбросов вредных веществ в окружающую среду и атмосферу.

2. В рамках реализации национального проекта «Экология» большая часть финансирования должна быть выделена на федеральный проект «Внедрение наилучших доступных технологий», который себя не оправдал.

3. Значимость внедрения зеленых технологий и снижения выбросов вредных веществ в окружающую среду промышленными предприятиями экономики Российской Федерации обусловлена тем, что такие действия сопровождаются оптимизацией финансовых, трудовых и материальных расходов. Себестоимость производства продукции снижается, а выручка и рентабельность - наоборот, повышаются. При этом внедрение принципов «зеленой экономики» обеспечивает промышленным компаниям следование модели устойчивого развития, что положительно сказывается на стоимости их бренда бизнеса при управлении балансом интересов стейкхолдеров.

\section{Библиографический список}

1. Охрана окружающей среды в России.URL: https://rosstat.gov.ru/storage/mediabank/nmV0UuE3/Ochrana_2020. pdf (дата обращения: 15.12.2021).

2. Основные показатели охраны окружающей среды. URL: https://rosstat.gov.ru/storage/mediabank/oxr_ bul_2021.pdf (дата обращения: 15.12.2021).

3. Национальный проект «Экология». URL: https://www.admrad.ru/wp-content/uploads/2019/07/07.pdf (дата обращения: 15.12.2021).

4. Направления работы Минприроды России. URL: https://www.mnr.gov.ru/activity/directions/ (дата обращения: 15.12.2021).

5. Федеральный проект «Внедрение наилучших доступных технологий».URL: https://wwf.ru/upload/iblock/876/ ndt.pdf (дата обращения: 15.12.2021).

6. Халил М.Р. Концепция зеленой экономики: основные положения и перспективы, экономические механизмы и условия перехода к зеленой экономике // Молодой ученый. 2018. № 45. С. 98-100. 